\title{
Role of mifepristone in induction of labour in pregnant women with previous lower section caesarean section with IUFD in late preterm and term pregnancies
}

\author{
Ram Kanwar Deora*, Nikhila G. Shetty
}

Department of Obstetrics and Gynecology, Umaid Hospital, Dr. S N Medical College, Jodhpur, Rajasthan, India

Received: 12 December 2016

Accepted: 07 January 2017

\section{*Correspondence:}

Dr. Ram Kanwar Deora,

E-mail: drramkanwar613@gmail.com

Copyright: $\odot$ the author(s), publisher and licensee Medip Academy. This is an open-access article distributed under the terms of the Creative Commons Attribution Non-Commercial License, which permits unrestricted non-commercial use, distribution, and reproduction in any medium, provided the original work is properly cited.

\begin{abstract}
Background: The objective of the study was to evaluate efficacy and safety of oral mifepristone for preinduction cervical ripening and induction of labour in late preterm and term pregnancies with previous caesarean section with intrauterine fetal demise

Methods: This prospective short term study was conducted at Umaid hospital SNMC Jodhpur Rajasthan January 2016 to November 2016. 100 subjects with previous uses beyond 34 week with intrauterine fetal demise and bishop's score $<6$ were included. Tablet mifepristone $200 \mathrm{mg}$ was given orally after taking written in informed consent. The same dose was repeated after 24 hour according to bishop's score. Analysis was done with respect to maternal outcome of vaginal delivery, CS, duration of labour.

Results: Among 100 subjects, 97 delivered vaginally (97\%) delivered within 72 hour of $1 \%$ dose. Improvement of bishop's score was observed in 1 subject (1\%), which later required augmentation by oxytocin followed by vaginal delivery. 1 subject $(2 \%)$ failed to respond and required caesarean section, 72 hour after given of $1^{\text {st }}$ dose.

Conclusions: Mifepristone can be used safely and effectively for induction of labour in previous one and two LSCS near term and term pregnancies to avoid CS rates.
\end{abstract}

Keywords: IUD, IOL, Mifepristone, Pregnancy, Previous CS

\section{INTRODUCTION}

As rates of CS are increasing globally, resulting increase the number of pregnancy with previous CS with periods, because of increasing in number of primary or repeated CS complications like (morbidly adherent placenta, rupture uterus, scar pregnancy, blood transfusions and anesthetic complications) are increasing. ${ }^{1,2}$ As developing countries have already poor resources, pregnancy with previous CS has deteriorate effect on economy of developing countries because of cost and other aspects. ${ }^{3}$

As number of pregnancies with previous LSCS increasing, more and more patients are presenting to obs/gynaec OPD, with frequents ANC visits and labour room for induction of labour for various indication and vaginal birth CS is a feasible option for these patients and many patients land up either emergency or elective LSCS for various indication. ${ }^{1-4}$

Patients with previous LSCS when undergone for induction of labour, associated with decreased successful outcome, when compared with spontaneous onset of labour and IOL also associated with scar dehiscence, rupture of uterus and consequently increase rate of fetal and maternal mortality and morbidity. ${ }^{4}$

According to Cochrane system, there is no ideal method of IOL with previous $\mathrm{CS}^{5}$ According to systematic review; metaanalysis over IOL with previous LSCS 
(scared uterus) is not possible because of paucity of evidences. ${ }^{6}$ Still there is no ideal method of IOL with previous LSCS and research is continue for IOL to achieve the goal to reduce rates of ERCS and over all CS rates. Mifepristone is an antiprogesterone agent used orally for IOL is still under investigations. According to Cochrane systematic review use of mifepristone for IOL has limited evidence in support but it is better than placebo to reduce CS rates. Mifepristone is not an oxytocis so it is not associated with over/hyper stimulation of uterus hence there is not increase the incidence of rupture uterus. ${ }^{7}$ Because of above stated benefit of mifepristone, we have selected a study to reduce the incidence of ERCS (elective repeat CS) and overall CS rates.

\section{METHODS}

This study was conducted at department of obstetrics and gynaecology Umaid hospital associated with Dr SN Medical College Jodhpur. All pregnant women with previous CS with IUD at term and near term from January 2016 to November 2016.

Inclusion criteria were singleton pregnancy, previous one and two LSCS, cephalic presentation and exclusion criteria were interconception period less than 18 month, estimated fetal weight more than $4 \mathrm{~kg}$, PROM, chorioamnitis and anaemia and other contraindication of vaginal delivers like CPD.

All benefits and risk associated with induction of labour and vaginal delivery after previous CS explained to patients and relatives and advantages and concerns regarding the use of mifepristone. After taking written and informed consent, patients received first dose of mifepristone $(200 \mathrm{mg})$ orally and second dose given at after 24 hour of first dose .Bishop score was associated after 24 and 48 hours of first dose. Only one patient required oxytocin augmentation. Intraoperative finding (I/D of CS, scar dehiscence), blood transfusion and subsequent hospital stay were recorded.

\section{RESULTS}

Table 1: Maternal outcome.

\begin{tabular}{|lll|}
\hline Maternal outcome & Number & Percentage \\
\hline Vaginal delivery & 97 & 97 \\
\hline LSCS & 1 & 1 \\
\hline Augmentation required & 1 & 1 \\
\hline Laparotomy & 1 & 1 \\
\hline Rupture uterus & 1 & 1 \\
\hline Blood transfusion & 1 & 1 \\
\hline ICU admission & 1 & 1 \\
\hline
\end{tabular}

During study periods total 100 pregnant women with previous CS (one(82) and two(18)) with IUFD with term and near term gestation received two doses of mifepristone $200 \mathrm{mg}$ orally, out of which 97 women's delivered vaginally within 72 hrs of first dose without any need of augmentation and 1 women delivered vaginally after oxytocin augmentation. One woman required CS because of failed trial. One woman went for emergency laparotomy for ruptured uterus which repaired (previous $2 \mathrm{CS}$ ); this patient further admitted in ICU and also required blood transfusion.

\section{DISCUSSION}

The IOL decreasing worldwide which leads to more and more pregnancy with previous CS ,increasing ERCS and its complications. ${ }^{1,2}$ In our study we observed that mifepristone is associated with favorable outcome in $97 \%$ of women's with previous CS with IUFD. According to various existing literature, the labor onset and cervical ripening observed. ${ }^{8-12}$ There is need of oxytocin requirement for augmentation of labour is very minimum so there is very less chances of scar dehiscence and rupture uterus. Mifepristone initiate the labour as naturally, causes cervical ripening (by releasing NO), promote uterine contractions by forming gap junctions and increasing influx of calcium it also increases the prostaglandins release without acting as a direct uterotonic. ${ }^{13-16}$

Informed consent was obtained from all patients for being included in study.

\section{CONCLUSION}

Mifepristone can be used safely and effectively for induction of labour in previous one and two LSCS near term and term pregnancies to avoid CS rates with very good efficacy, there is very less complications due to minimum use of oxytocis. Blood transfusion requirement also minimum and anaesthesia related complications avoided very effectively.

Funding: No funding sources

Conflict of interest: None declared

Ethical approval: The study was approved by the Institutional Ethics Committee

\section{REFERENCES}

1. Arulkumaran S. Caesarean section rates are increasing worldwide. Preface. Best Pract Res Clin Obstet Gynaecol. 2013;27(2):151-2.

2. Timor-Tritsch IE, Monteagudo A, Santos R. The diagnosis, treatment, and followup of cesarean scar pregnancy. Am J Obstet Gynecol. 2012;207:1-13.

3. Niino $Y$. The increasing cesarean rate globally and what we can do about it. Biosci Trends. 2011;5(4):139-50.

4. ACOG Practice bulletin no. 115. Vaginal birth after previous cesarean delivery. American College of Obstetricians and Gynaecologist. Obstet Gynecol. 2010;116(4):450-63. 
5. Jozwiak M, Dodd JM. Methods of term labor induction for women with a previous Caesarean section. Cochrane Database Syst Rev. 2013.

6. Dodd J, Crowther C. Induction of labor for women with a previous Caesarean birth: a systematic reviewof literature. Aust N Z J Obstet Gynaecol. 2004;44(5):392-5.

7. Hapangama D, Neilson JP. Mifepristone for induction of labour. Cochrane Database Syst Rev. 2009.

8. McGill J, Shetty A. Mifepristone and misoprostol in induction of labor at term. Int $\mathrm{J}$ Gynaecol Obstet. 2007;96(2):80-4.

9. Stenlund PM, Ekman G, Aedo AR. Induction of labor with mifepristone-a randomized, double-blind study versus placebo. Acta Obstet GynecolnScand. 1999;78(9):793-8.

10. Li L, Gao W, Chen S. Labour induction in women at term with mifepristone and misoprostol. Zhonghua Fu Chan Ke Za Zhi. 1996;31(11):681-4.

11. Lelaidier C, Baton C, Benifla JL. Mifepristone for labour induction after previous caesarean section. $\mathrm{Br}$ J Obstet Gynaecol. 1994;101(6):501-3.

12. Zhang N, Hu Y. Labour induction in women at term with mifepristone and its safety. $\mathrm{Z}$ honghua $\mathrm{Fu}$ Chan Ke Za Zhi. 1999;34(12):751-3.
13. Brogden RN, Goa KL, Faulds D. Mifepristone. A review of its pharmacodynamic and pharmacokinetic properties, and therapeutic potential. Drugs. 1993;45:384-409.

14. Chwalisz K, Garfield RE. New molecular challenges in the induction on cervical ripening. Hum Reprod. 1998;13:245-52.

15. Garfield RE, Blennerhassett MG, Miller SM. Control of myometrial contractility: role and regulation of junctions. Oxf Rev Reprod Biol. 1988;10:436-90.

16. Cheng L, Kelly RW, Thong KJ. The effects of mifepristone (RU486) on prostaglandin dehydogenase in decidual and chorionic tissue in early pregnancy. Hum Reprod. 1993;8:705-9.

17. Cheng L, Kelly RW, Thong KJ. The effect of mifepristone (RU486) on the immunohistochemical distribution of prostaglandin $\mathrm{E}$ and its metabolite in decidual and chorionic tissue in early pregnancy. $\mathrm{J}$ Clin Endocrinol Metab. 1993;77:873-7.

Cite this article as: Deora RK, Shetty NG. Role of mifepristone in induction of labour in pregnant women with previous lower section caesarean section with IUFD in late preterm and term pregnancies. Int $\mathbf{J}$ Reprod Contracept Obstet Gynecol 2017;6:707-9. 